\title{
Pinturas antiincrustantes derivadas de plantas terrestres: una solución segura para el ambiente en el control de la bioincrustación
}

\author{
Antifouling paints derived from terrestrial plants: a safe solution for \\ the environment in the control of biofouling
}

Tintas anti-incrustantes derivadas de plantas terrestres: uma solução segura para o meio ambiente no controle da bioincrustação

Vanessa Ochi Agostini ${ }^{1}$, https://orcid.org/0000-0002-8325-254X

Grasiela Lopes Leães Pinho ${ }^{1}$ https://orcid.org/0000-0001-7951-0334

Erik Muxagata $^{2}$ http://orcid.org/0000-0002-4210-5252

Alexandre José Macedo ${ }^{3}$ https://orcid.org/0000-0002-8951-4029

Fabiana Rey Bentos ${ }^{4}$ https://orcid.org/0000-0001-5931-5902

Lucía Boccardi ${ }^{4}$ https://orcid.org/0000-0002-5391-2308

María Jesús Dabezies ${ }^{5}$ https://orcid.org/0000-0001-9909-3427

Ernesto Brugnoli ${ }^{6}$ https://orcid.org/0000-0001-7304-1856

*Autor de contacto: nessaochi@gmail.com

${ }^{1}$ Laboratório de Microcontaminantes Orgânicos e Ecotoxicologia Aquática - Programa de Pós-Graduação em Oceanologia - Instituto de Oceanografia - Universidade Federal do Rio Grande, Rio Grande do Sul, Brasil

${ }^{2}$ Laboratório de Zooplâncton - Programa de Pós-Graduação em Oceanografia Biológica - Instituto de Oceanografia - Universidade Federal do Rio Grande, Rio Grande do Sul, Brasil

${ }^{3}$ Laboratório de Biofilmes e Diversidade Bacteriana - Centro de Biotecnologia Universidade Federal do Rio Grande do Sul, Rio Grande do Sul, Brasil

${ }^{4}$ Latitud-Fundación LATU, Montevideo, Uruguay

${ }^{5}$ Laboratorio Tecnológico del Uruguay (LATU), Montevideo, Uruguay

${ }^{6}$ Oceanografía y Ecología Marina, Facultad de Ciencias, Universidad de la República, Montevideo, Uruguay

Recepción: 14 Agosto 2020 Aprobación: 15 Enero 2021

Esta obra está bajo una Licencia Creative Commons Atribución-NoComercial 4.0 Internacional. 
Resumen: Los invertebrados (por ejemplo, cirripedios y mejillones) son los principales responsables de las pérdidas económicas a nivel industrial y naval de la bioincrustación, agravada por la colonización de especies invasoras (por ejemplo, el mejillón dorado, Limnoperna fortunei). Se han utilizado diversas estrategias para controlar la bioincrustación. Sin embargo, no son eficientes o causan una alta mortalidad de organismos acuáticos, incluso las tintas antiincrustantes. Actualmente, con la necesidad de preservar la salud humana y ambiental, se han enfocado en la investigación de nuevos agentes naturales para reemplazar las moléculas sintéticas tóxicas de estas pinturas. El estudio de productos naturales bioactivos a partir de plantas terrestres ha sido una opción prometedora en el campo clínico y puede tener el mismo potencial en el acuático. Así, la principal pregunta de este estudio es: ¿Cómo seleccionar los extractos y compuestos más prometedores? Este trabajo analizó artículos publicados sobre el tema con el objetivo de resaltar la información necesaria para centrar las investigaciones en antiincrustantes derivados de plantas terrestres. Se examinaron 29 artículos entre 1990 y 2020. Los productos naturales derivados de plantas terrestres tienen un gran potencial como antiincrustantes sostenibles, inhibiendo la colonización de micro y macrofouling. Los compuestos alcaloides y flavonoides de las familias Zingiberaceae, Myrtaceae y Fagaceae ya han mostrado resultados prometedores contra mejillones.

Palabras clave: compuestos naturales, extractos naturales, fitoquímicos, invertebrados, mejillón.

Abstract: Invertebrates (e.g, barnacles, mussels) are usually the main responsible for the industrial and naval high economic costs of biofouling, aggravated by colonization of invasive species such (e.g., golden mussel, Limnoperna fortunei). Many strategies have been used as attempts to control biofouling. However, these are not efficient or cause high mortality of aquatic organisms, including the antifouling coatings. Currently, with the aim of preserving human and environmental health, new studies have focused on the discovery of new natural agents to replace the toxic synthetic molecules in paints. The study of bioactive natural products from terrestrial plants has been a promising option in the clinical field and they can have the same potential in the aquatic field. In this way, the main question of this study is: How to select the most promising extracts and compounds? This review evaluated the documents published on this topic, with the aim of highlighting the information necessary to focus antifouling investigations derived from terrestrial plants. A total of 29 papers were examined in this review from 1990 to 2020. Natural products derived from terrestrial plants have great potential as sustainable antifouling, inhibiting colonization of micro and macrofouling. Alkaloid and flavonoid compounds from the Zingiberaceae, Myrtaceae and Fagaceae families have already shown promising results against mussels.

Keywords: natural product, natural extract, phytochemical, invertebrates, mussel.

Resumo: Invertebrados (por exemplo, cirripédios, mexilhões) são os principais responsáveis pelos prejuízos econômicos industriais e navais da bioincrustação, agravados pela colonização de espécies invasoras (por exemplo, mexilhão dourado, Limnoperna fortunei). Muitas estratégias têm sido usadas para controlar a bioincrustação. 
No entanto, não são eficientes ou causam alta mortalidade de organismos aquáticos, incluindo as tintas anti-incrustantes. Atualmente, com $<$ a necessidade de preservar a saúde humana e ambiental têm se concentrado na investigação de novos agentes naturais para substituir as moléculas sintéticas tóxicas dessas tintas. O estudo de produtos naturais bioativos de plantas terrestres tem sido uma opção promissora no campo clínico e elas podem ter o mesmo potencial no campo aquático. Desse modo, a principal pergunta deste estudo é: Como selecionar os extratos e compostos mais promissores? Este trabalho analisou artigos publicados sobre este tópico, com o objetivo de destacar as informações necessárias para focalizar a pesquisa em anti-incrustantes derivados de plantas terrestres. Foram examinados 29 artigos de 1990 a 2020. Os produtos naturais derivados de plantas terrestres têm um grande potencial como antiincrustantes sustentáveis, inibindo a colonização de micro e macro-organismos. Compostos alcalóides e flavonóides das famílias Zingiberaceae, Myrtaceae e Fagaceae já apresentaram resultados promissores contra mexilhões.

Palavras-chave: compostos naturais, extrato natural, fitoquímicos, invertebrados, mexilhão.

\section{INTRODUCCIÓN}

La fijación y el crecimiento de organismos acuáticos en sustratos consolidados se conoce como bioincrustación (Nandakumar y Yano, 2003). El proceso de bioincrustación comienza con la adsorción de moléculas orgánicas en superficies sumergidas y la posterior colonización de especies bacterianas que producen una sustancia polimérica extracelular (SPE) para formar un biofilm (biopelícula) (Agostini, et al., 2018). Durante el proceso de bioincrustación, varios organismos como virus, hongos, microalgas, protozoos, esporas de algas y meroplancton (por ejemplo, larvas de invertebrados) se depositan en los sustratos, iniciando una sucesión ecológica y dependiente del acople bentopelágico (Agostini, et al., 2017; 2018).

La bioincrustación es un problema económico grave ya que daña las estructuras artificiales sumergidas en el medio acuático como embarcaciones, ductos y plataformas (Schultz, et al., 2011). Este proceso no es nuevo; existen registros desde la antigüedad (WHOI, 1952). Las pérdidas económicas globales debido a la bioincrustación marina fueron de quince mil millones de dólares en 2001 (Azis, et al., 2001). Esto incluye el costo de su prevención, el mantenimiento de la infraestructura (biocorrosión, aumento de peso y obstrucción), y el consumo de combustible (Schultz, et al., 2011).

Los invertebrados son los principales responsables de los altos costos de la bioincrustación, principalmente asociados a la colonización de cirripedios y mejillones (Dobretsov y Rittschof, 2020). Los problemas aumentan cuando se asocian a la colonización de especies invasoras como el mejillón dorado, Limnoperna fortunei (Uliano-Silva, et al., 2018). Esta especie es un bivalvo 
originario del sudeste asiático que se introdujo accidentalmente en América del Sur a principios de la década de 1990 (Maranhão y Stori, 2019). El establecimiento del mejillón dorado en América del Sur está relacionado con la facilidad de adaptación y la alta tasa de reproducción (Uliano-Silva, et al, 2018; Maranhão y Stori, 2019). Y sus impactos económicos están relacionados con la obstrucción de tuberías de captación de agua, filtros y sistemas de enfriamiento en plantas e industrias hidroeléctricas, sistemas de drenaje de aguas pluviales, daños a motores y embarcaciones, causados por incrustación y consecuente biocorrosión, cambio de forma y aumento de peso de estas estructuras (Boltovskoy y Correa, 2015; Maranhão y Stori, 2019). Después de 30 años de que el mejillón dorado invadió América del Sur, no hay signos de que esta invasión esté bajo control o incluso se esté estabilizando (Uliano-Silva, et al., 2018). Se han utilizado diversas estrategias para el control de esta especie.

La Tabla 1 presenta las principales estrategias de control utilizadas para mitigar las abundancias del mejillón dorado en sistemas invadidos (por ejemplo, tuberías de agua).

Tabla 1. Principales estrategias de control utilizadas contra el mejillón dorado (Limnoperna fortunei).

\begin{tabular}{|cc|}
\hline \begin{tabular}{|l} 
Estrategias de control \\
Velocidades rápidas de flujo $(>1.5 \mathrm{~m} / \mathrm{s})$
\end{tabular} & Jutor \\
\hline Campos magnéticos, et al. (1998) & Jenner, et al. (1998) \\
\hline Corriente eléctrica & Katsuyama, et al. (2005) \\
\hline Acústica por ultrasonido & Santos, et al. (2012) \\
\hline Filtración & Claudi, et al. (2014) \\
\hline Luz ultravioleta & Perepelizin y Boltovskoy (2014) \\
\hline Uso de depredadores (por ejemplo, peces) & Boltovskoy y Correa (2015) \\
\hline Turbulencia & Claudi y Oliveira (2015) \\
\hline Inyección de ozono & Maranhão y Stori (2019) \\
\hline
\end{tabular}

Sin embargo, todas estas estrategias no son eficientes o causan una alta mortalidad de larvas y deformación en los sobrevivientes (Breitig, 1965; Katsuyama, et al., 2005; Santos, et al., 2012). Otra estrategia es el control químico utilizando superficies pintadas con antiincrustantes (Fujita, et al., 2015). Aunque 
se han desarrollado diversas pinturas antiincrustantes para abordar el problema de la bioincrustación (Telegdi, et al., 2016), una alternativa antiincrustante ecológicamente segura y eficiente aún no está disponible en el mercado (Konstantinou y Albanis, 2004; Agostini, et al., 2018). La eficacia real de las sustancias antiincrustantes es una preocupación importante, ya que estas actúan sobre los organismos en etapas sucesivas avanzadas, pero no garantizan la eficiencia durante todo el proceso (Teixeira, 2010). Este proceso requiere la eliminación mecánica de incrustaciones periódicamente y la aplicación posterior de pinturas (Desai, 2008; Teixeira, 2010).

Las estrategias antiincrustantes en todo el mundo incluyen pinturas con biocidas derivados de compuestos orgánicos, inorgánicos y metálicos (Telegdi, et al., 2016). Además, el ambiente acuático está bajo presión constante debido a la contaminación química y la toxicidad de los compuestos antiincrustantes tradicionales (por ejemplo, Cu, Zn, DCOIT), comprometiendo así la calidad del agua (Soroldoni, et al., 2017). La función de un biocida es evitar el asentamiento de organismos en las superficies al matarlos. Sin embargo, están asociados con una alta toxicidad para los organismos objetivo y no objetivo (Amara, et al., 2018) debido a la lixiviación de los biocidas al ambiente acuático.

Actualmente, con el objetivo de preservar la salud humana y ambiental, incluyendo la calidad del agua, es importante promover el descubrimiento de nuevos agentes naturales para reemplazar las moléculas sintéticas tóxicas (Fernández-Niño e Islam, 2017). En la investigación de bioincrustaciones, muchos extractos naturales han sido probados como reemplazos de biocidas tóxicos en pinturas antiincrustantes, presentando resultados prometedores (Salta, et al., 2013).

Los compuestos naturales son sintetizados por organismos en respuesta a condiciones ambientales extremas (Malafaia, et al., 2017). De esta manera, las plantas terrestres bajo estrés podrían ser una fuente de diferentes compuestos. Estos compuestos podrían usarse como ingredientes activos en formulaciones antiincrustantes (Maréchal y Hellio, 2009). Los estudios sobre el potencial antiincrustante del uso de productos naturales derivados de plantas terrestres son escasos (Gopikrishnan, et al., 2015; Agostini, et al., 2019; 2020). En contraste, el estudio de productos naturales bioactivos a partir del metabolismo secundario de plantas terrestres ha sido una opción prometedora en el campo clínico como defensa química contra los biofilms (Trentin, et al., 2011; Malafaia, et al., 2017). Además, pueden tener el mismo potencial en el campo acuático, inhibiendo la bioincrustación; evitando, por ejemplo, el asentamiento del mejilón dorado. Además, el uso de productos naturales de origen terrestre para producir nuevas tecnologías antiincrustantes puede introducir un concepto innovador en el mercado para disminuir los impactos en la calidad del agua (Soroldoni, et al., 2017). 
Así, la principal pregunta relacionada con los productos bioactivos de plantas terrestres como alternativa antiincrustante es: ¿Cómo seleccionar los extractos y compuestos más prometedores? Este trabajo realizó una revisión de los artículos publicados sobre el tema, con el objetivo de resaltar la información necesaria para centrar las investigaciones antiincrustantes en productos prometedores de plantas terrestres. Complementariamente, se buscó información sobre posibles productos que pueden tener una acción enfocada contra el mejillón dorado.

\section{MATERIALES Y MÉTODOS}

Se realizó una revisión de literatura utilizando Periódicos Capes, una base de datos que comprende colecciones que incluyen Scopus, Web of Science y Science Direct Journals. Para identificar los artículos se utilizaron combinaciones de palabras clave en inglés: (Terrestrial plants) AND (Natural products) AND (Antifouling); (Terrestrial plants) AND (Bioactive compounds) AND (Antifouling); (Phytochemical) AND (Antifouling). Los documentos recopilados fueron seleccionados de acuerdo con los siguientes criterios obligatorios: ser publicado en inglés o español en una revista indexada revisada por pares e informar la investigación de productos de plantas terrestres como alternativa antiincrustante. La literatura gris, como tesis y disertaciones, resúmenes de congresos e informes técnicos, no se consideró en esta revisión. Todas las referencias citadas en estos documentos también se seleccionaron y se ajustaron a los criterios establecidos.

A partir de la mencionada búsqueda se organizaron los trabajos identificados de acuerdo con el tipo de tratamiento, las familias de plantas terrestres identificadas, las secciones de plantas consideradas para tratamiento, los compuestos de moléculas activas y el tipo de biofouling considerado para el ensayo (macrofouling y microfouling). Se realizó un análisis de correspondencia para ordenar los datos antes mencionados con el fin de encontrar correspondencia entre ellos, utilizando el programa PAST 3.25 (Hammer y Harper, 2006).

\section{RESULTADOS Y DISCUSIÓN}

Se examinaron 604 artículos, y 29 se analizaron en detalle, considerando el período entre 1990 y marzo de 2020. La mayoría de los tratamientos citados en base a plantas terrestres para inhibir la bioincrustación se concentró en ensayos (92\%) y el $8 \%$ en revisiones de literatura. Entre los productos naturales derivados de plantas terrestres, $38 \%$ fueron probados in situ y $62 \%$ en laboratorio. La mayoría de los estudios (50\%) se centró en los efectos de fitoquímicos específicos (compuestos o moléculas), el $47 \%$ en efectos del extracto crudo y el $3 \%$ ha ensayado ambos. La mayoría de las pruebas se realizaron para evaluar el potencial antiincrustante contra los invertebrados (69\%) y contra microorganismos (40\%), o ambos. Solo el $36 \%$ de los estudios evaluó los efectos toxicológicos de los 
tratamientos. La Figura 1 presenta el rango de artículos publicados y los tratamientos probados, utilizando productos naturales derivados de plantas terrestres como posibles antiincrustantes.

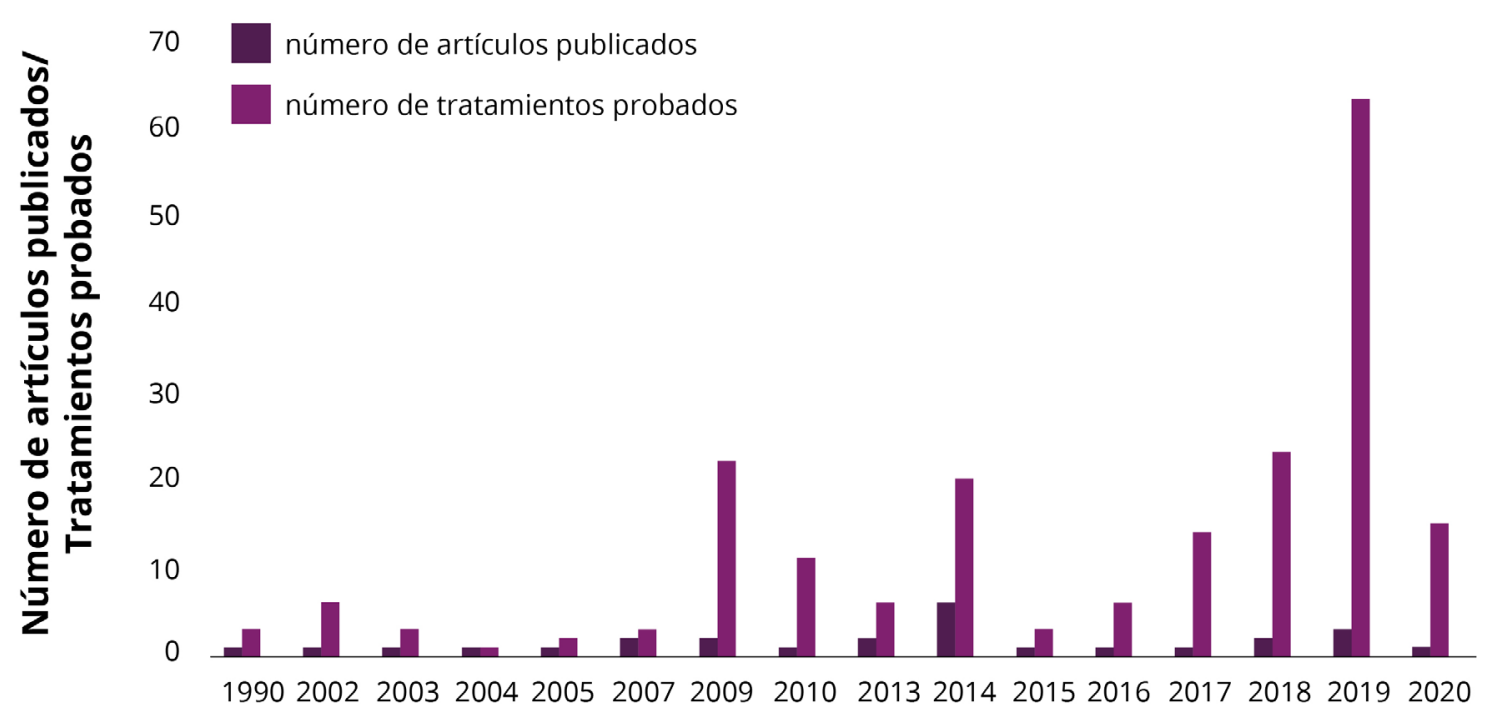

Años

Figura 1. Número de artículos publicados y número de tratamientos probados sobre el uso de productos naturales de plantas terrestres como posibles antiincrustantes.

Como se puede observar en la Figura 1, el número de tratamientos antiincrustantes probados derivados de plantas terrestres a lo largo del tiempo ha fluctuado, con un aumento a partir de 2009. El máximo registrado se identifica en 2019, con un número bajo y constante de publicaciones desde 1990, con el mayor número de publicaciones registradas en 2014. Según Omae (2003), en la década de 1980 se exploraron extractos de plantas terrestres como fuente de compuestos antiincrustantes, pero fueron reemplazados por investigaciones sobre organismos marinos en la década de 1990 (Gopikrishnan, et al., 2015). Con respecto a la bioincrustación acuática, la mayoría de los extractos de plantas y compuestos analizados provenían de algas marinas (Cho, et al., 2001; Manilal, et al., 2010; Prabhakaran, et al., 2012; Dahms y Dobretsov, 2017). Algunos estudios analizaron extractos crudos de plantas terrestres, o compuestos aislados contra la bioincrustación inicial (Devi, et al., 1997; Prabhakaran, et al., 2012; Liu, et al., 2019) o tardía (Goransson, et al., 2004; Zhou, et al., 2009; Moodie, et al., 2018). Prabhakaran y otros (2012) compararon extractos de plantas acuáticas y terrestres contra cepas de bacterias aisladas de biofilm, y observaron que el extracto de plantas terrestres tenía una mayor actividad inhibidora contra el biofilm que las algas y los pastos marinos. Esto demuestra la importancia de investigar extractos de plantas de ambientes terrestres (Agostini, et al., 2020). Sin embargo, si el número de estudios con plantas terrestres como antiincrustantes es bajo, cabe 
hacerse la siguiente pregunta: ¿Por qué evaluar el potencial de los productos naturales derivados de plantas terrestres como posibles antiincrustantes?

Las plantas han desarrollado un complejo sistema de defensa que comprende una complicada gama de productos químicos (Boy, et al., 2018); y diversas plantas terrestres se han utilizado como medicina alternativa en todo el mundo, lo que demuestra las actividades clínicas antibacterianas y antibiofilm (Malafaia, et al., 2017). Las plantas terrestres son más fáciles de muestrear, y es posible cultivarlas, lo que permite un mayor número de ensayos y evaluaciones de forma sostenida (Agostini, et al., 2019), con varias formas conocidas de extraer los compuestos de interés (Agostini, et al., 2020).

Además, de los tratamientos evaluados en esta revisión de literatura surge que el $32 \%$ presentó resultados satisfactorios, y el 19\%, resultados parcialmente satisfactorios. En el Anexo 1 se presenta la información de los tratamientos que obtuvieron resultados satisfactorios en la inhibición de la bioincrustación.

¿Qué familias y especies de plantas terrestres son responsables de los efectos antiincrustantes? Entre los tratamientos con resultados satisfactorios de inhibición de la bioincrustación, las familias Fabaceae, Anacardiaceae, Arecaceae, Zingiberaceae y Rutaceae se destacaron por presentar al menos cuatro pruebas y el 30\% o más con resultados positivos (Figura 2).

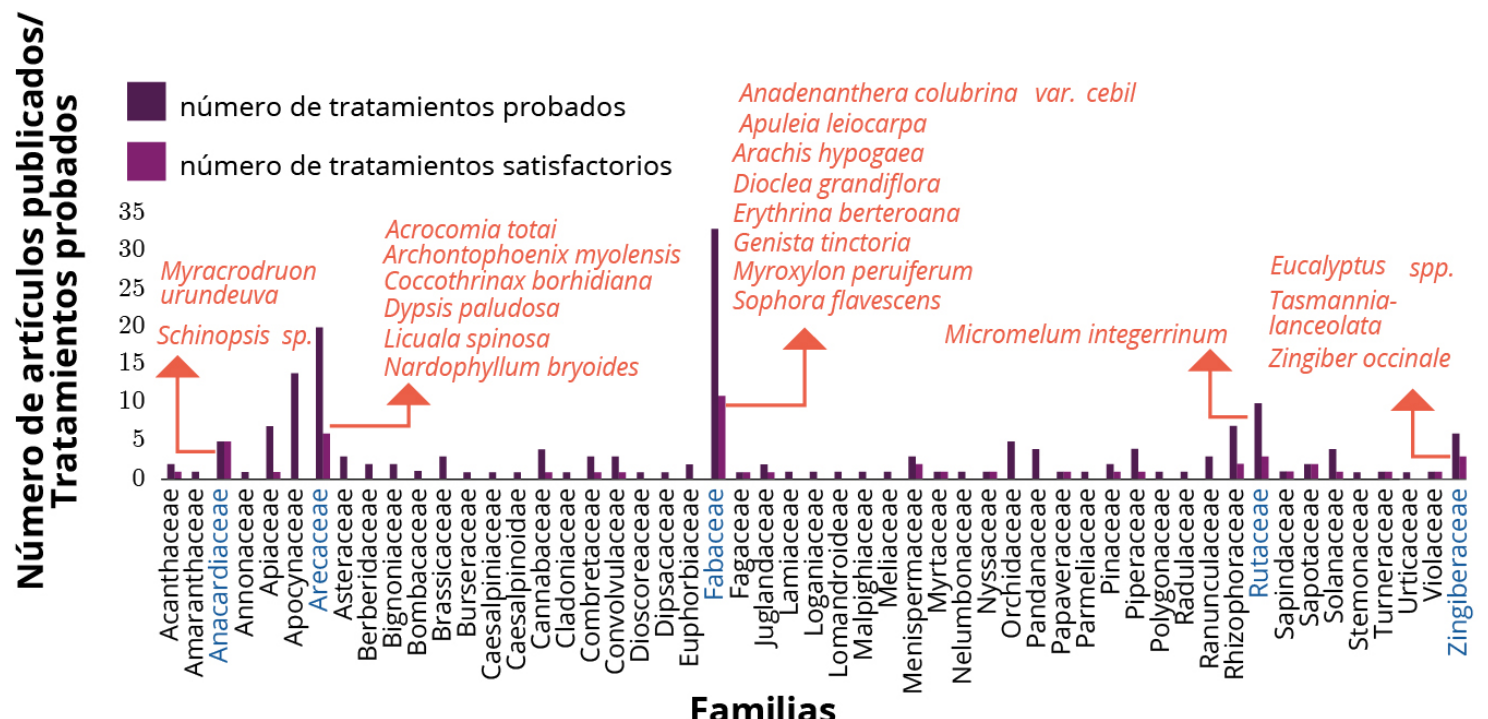

Figura 2. Familias y especies de plantas terrestres evaluadas como posibles antiincrustantes. Las familias con resultados más satisfactorios se indican en azul.

La mayoría de los resultados satisfactorios se observaron en ocho especies de la familia Fabaceae, pertenecientes a ocho géneros diferentes (Stupak, et al., 2003; Zhou, et al., 2009; Qian, et al., 2010; Feng, et al., 2018; Agostini, et al., 2019; Clasen 
y Kesel, 2019). La familia Fabaceae, también llamada Leguminosae, es una de las familias botánicas más grandes e importantes (Di Stasi e Hiruma-Lima, 2002), y está compuesta por aproximadamente 19.000 especies distribuidas en 695 géneros (Giulietti, et al., 2005). Esta familia está formada por árboles, arbustos, lianas y hierbas, y tiene una distribución cosmopolita (Di Stasi e Hiruma-Lima, 2002).

La familia Anacardiaceae también mostró resultados antiincrustantes positivos para dos especies, pertenecientes a dos géneros (Stupak, et al., 2003; Pérez, et al., 2007; Zhou, et al., 2009; Qian, et al., 2010; Bellotti, et al., 2014; Agostini, et al., 2020). Anacardiaceae es una familia compuesta por unos 76 géneros y 850 especies de árboles y arbustos, más raramente de lianas y hierbas perennes, distribuidas principalmente en áreas tropicales y subtropicales de todo el mundo (Pell, et al., 2011); y ha sido muy prometedora en la búsqueda de sustancias bioactivas (Correia, et al., 2006; Agra, et al., 2007).

Otra familia con resultados satisfactorios es Arecaceae. Seis especies de esta familia, pertenecientes a seis géneros diferentes, mostraron resultados positivos de inhibición de la bioincrustación (Pérez, et al., 2014; Clasen y Kesel, 2019). Esta familia está compuesta por 200 géneros y aproximadamente 2.800 especies (Medeiros-Costa, 2002), siendo popularmente compuesta de palmeras con gran variedad morfológica. La familia Zingiberaceae también mostró resultados antiincrustantes satisfactorios asociados con tres especies de plantas, pertenecientes a tres géneros (Etoh, et al., 2002). Zingiberaceae es la familia más grande de plantas herbáceas perennes, la cual contiene aproximadamente 1.400 especies divididas en 47 géneros (Holtum, 1950). Las especies están ampliamente distribuidas y se utilizan como remedio tradicional en los trópicos debido a sus fitoquímicos (Pancharoen, et al., 2000).

Una especie de la familia Rutaceae también mostró la capacidad de inhibir la bioincrustación (Zhou, et al., 2009). La familia Rutaceae tiene alrededor de 140 géneros y 2.000 especies (Cabral, et al., 2012); está compuesta por hierbas, arbustos y pequeños árboles que crecen en todas partes del mundo (Sandjo, et al., 2014; Sichaem, et al., 2014), y se usa en medicina tradicional para el tratamiento de enfermedades (Sandjo, et al., 2014).

¿Cuáles son los principales lugares de origen de las plantas terrestres responsables de los efectos antiincrustantes, y qué partes de las plantas presentan mayor actividad? En relación con los principales lugares de origen de las plantas con resultados antiincrustantes satisfactorios, el $85 \%$ se puede encontrar en regiones tropicales, el $38 \%$ en regiones subtropicales y solo el $12 \%$ en regiones templadas. Algunas de las plantas se distribuyen en más de un área geográfica. Entre los países de la colección, se destacan Brasil, China, Argentina e India. Entre los tratamientos probados con resultados más satisfactorios en la 
inhibición de la bioincrustación, se destacan los extractos crudos, compuestos o moléculas derivados de frutos, semillas (órganos reproductivos) y hojas (órganos vegetativos) (Figura 3).

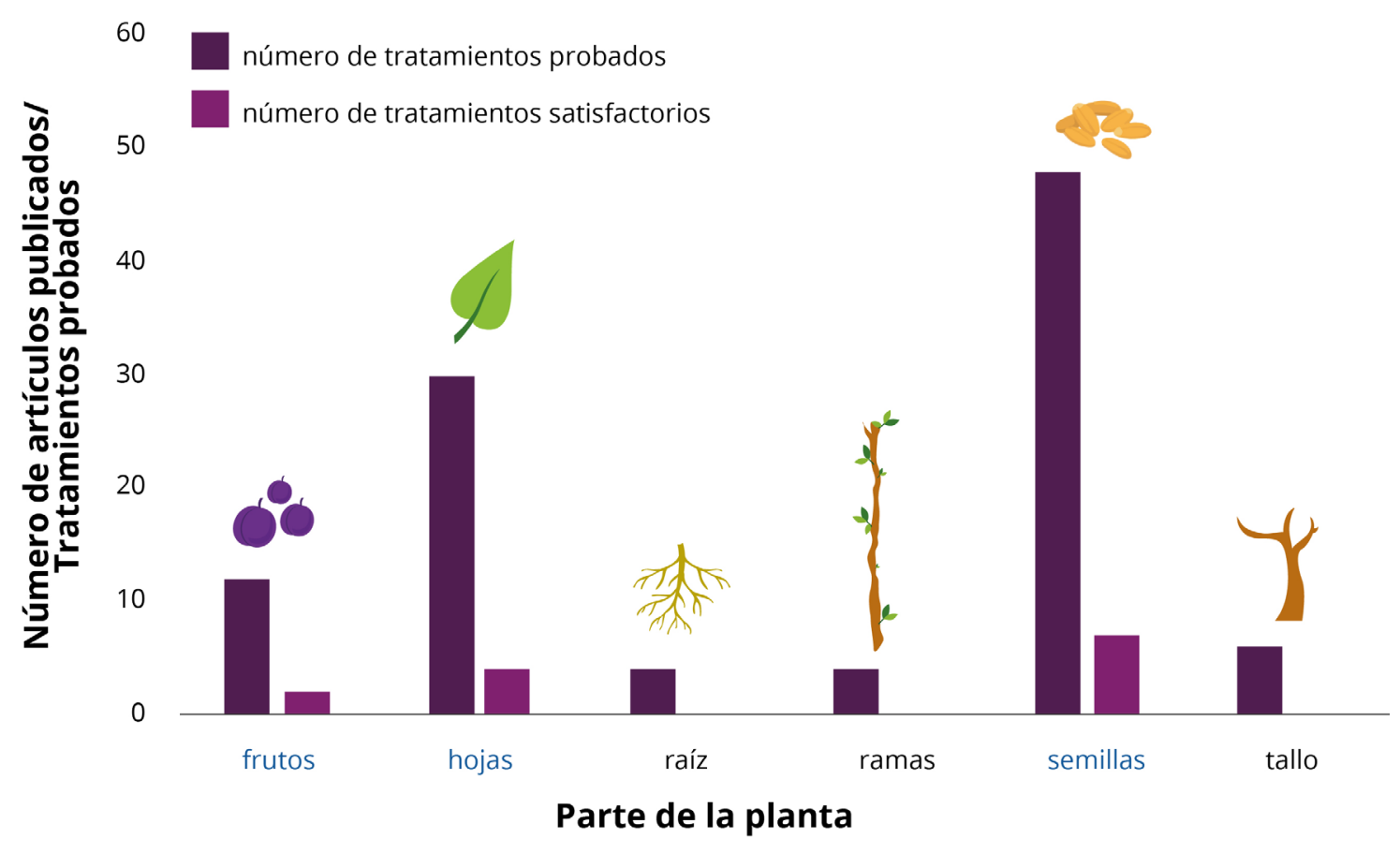

Figura 3. Parte de plantas terrestres evaluadas como posibles antiincrustantes. Las partes con los resultados más satisfactorios se indican en azul

Los frutos de las plantas tienen como función básica proteger, conservar y garantizar el desarrollo de las semillas. Su forma está estrechamente vinculada a su forma de polinización (Raven, et al., 1992). Las frutas presentan diferentes compuestos bioactivos con acción antimicrobiana (Liu, 2004; Karasawa y Mohan, 2018). Las semillas tienen un fuerte mecanismo de defensa, posiblemente debido a la presencia de fito-constituyentes que contribuyen a la actividad antioxidante y antimicrobiana (Kothari y Seshadri, 2010). Existen numerosos informes en la literatura sobre la presencia de sustancias bioactivas en semillas de plantas que sirven como atrayentes para dispersar semillas de animales (Kothari y Seshadri, 2010). La función principal de las hojas es capturar la luz solar para fabricar reservas de alimentos e intercambio de gases (fotosíntesis y respiración), además son transpirables. La cantidad y la calidad de las hojas de las plantas pueden cambiar estacionalmente. Las hojas también pueden adaptarse para realizar otras funciones en la planta, como la defensa a través de la producción de sustancias tóxicas (Appezzato-da-Glória, et al., 2006). Los extractos de raíces, ramas y tallos, como se muestra en la Figura 3 , no se consideraron antiincrustantes satisfactorios.

¿Cuáles son los compuestos y moléculas más activos derivados de plantas terrestres con efectos antiincrustantes? Entre los resultados obtenidos en los 
estudios incluidos en esta revisión, los flavonoides, taninos y alcaloides fueron los compuestos responsables de los porcentajes más altos de tratamientos antiincrustantes satisfactorios (Figura 4).

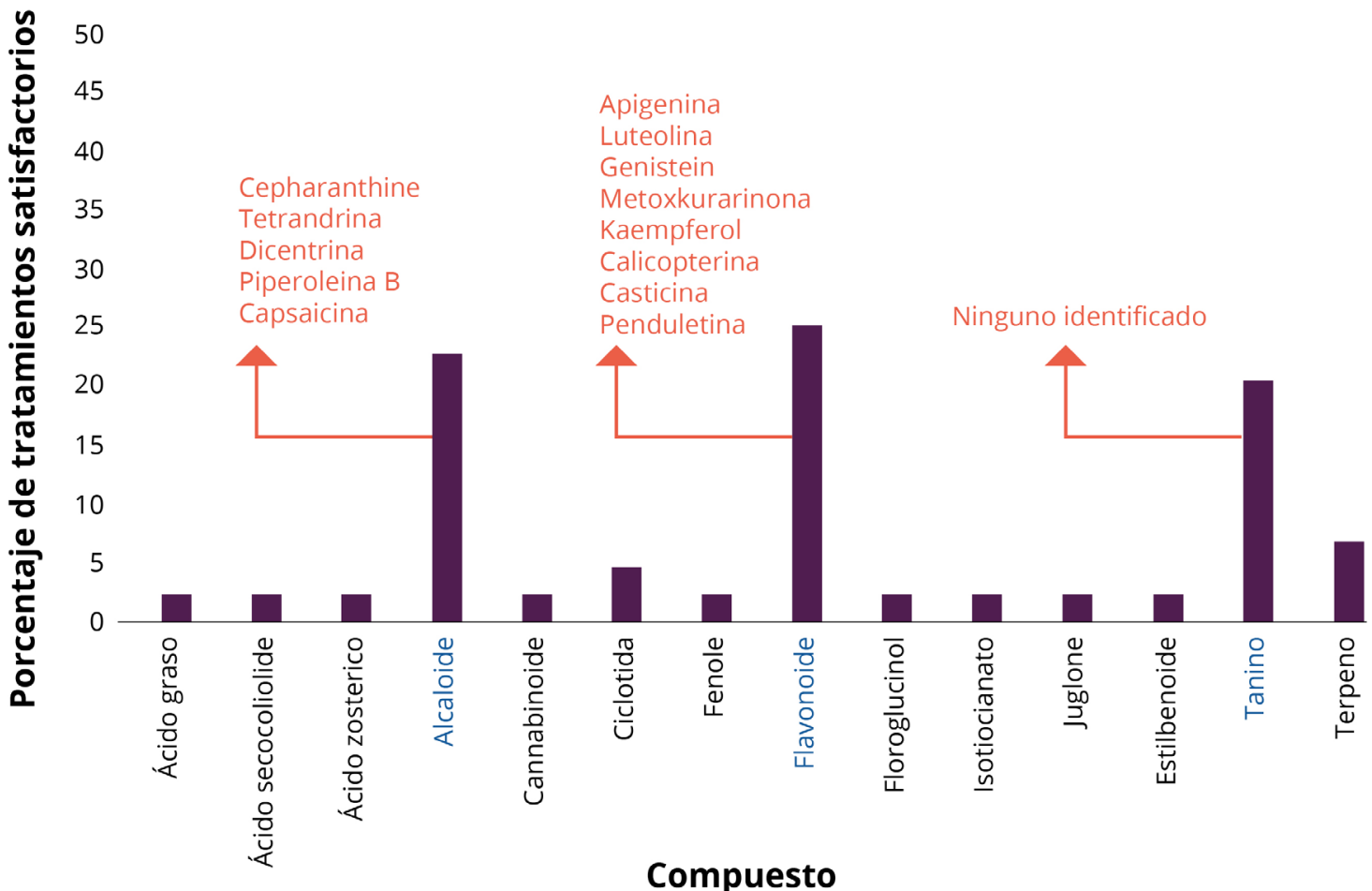

Figura 4. Compuestos químicos y moléculas derivadas de plantas terrestres con actividades antiincrustantes satisfactorias. Los compuestos químicos con los resultados más satisfactorios se indican en azul.

Los alcaloides son compuestos nitrogenados ampliamente distribuidos en diferentes grupos de plantas (Cordell, 1981). Farmacológicamente activos, son derivados de aminoácidos que contienen uno o más átomos de nitrógeno heterocíclicos. Los alcaloides en las plantas sirven como agentes anti-herbívoros, quimioprotectores o como reguladores del crecimiento (Buchanan, et al., 2000). Se han usado alcaloides en forma de extractos de plantas para venenos, narcóticos, estimulantes y medicamentos durante varios miles de años. Por lo tanto, muchas de las drogas comunes que se usan en la actualidad están basadas en alcaloides. Debido a esta complejidad química, los alcaloides a menudo se obtienen de la fuente de la planta en lugar de producirse sintéticamente (Cseke, et al., 2006).

Los alcaloides son compuestos nitrogenados ampliamente distribuidos en diferentes grupos de plantas (Cordell, 1981). Farmacológicamente activos, son derivados de aminoácidos que contienen uno o más átomos de nitrógeno heterocíclicos. Los alcaloides en las plantas sirven como agentes anti-herbívoros, quimioprotectores o como reguladores del crecimiento (Buchanan, et al., 2000). 
Se han usado alcaloides en forma de extractos de plantas para venenos, narcóticos, estimulantes y medicamentos durante varios miles de años. Por lo tanto, muchas de las drogas comunes que se usan en la actualidad están basadas en alcaloides. Debido a esta complejidad química, los alcaloides a menudo se obtienen de la fuente de la planta en lugar de producirse sintéticamente (Cseke, et al., 2006).

Los flavonoides tienen dos anillos de benceno separados por una unidad de propano y derivan de la flavona. Generalmente son compuestos solubles en agua. Los compuestos más conjugados son a menudo de colores brillantes. Generalmente se encuentran en plantas como sus glucósidos, lo que puede complicar las determinaciones de la estructura. Las diferentes clases dentro del grupo se distinguen por los anillos heterocíclicos adicionales que contienen oxígeno y grupos hidroxilos (Williams y Grayer, 2004).

Los taninos son oligómeros solubles en agua, ricos en grupos fenólicos, capaces de unir o precipitar proteínas solubles en agua (Hagerman y Butler, 1989). Los taninos, comunes a las plantas vasculares, existen principalmente dentro de los tejidos leñosos, pero también se pueden encontrar en las hojas, flores o semillas. Los tejidos vegetales que tienen un alto contenido de tanino poseen un sabor muy amargo, y la mayoría de los alimentadores los evitan (Cseke, et al., 2006). Ningún estudio ha identificado moléculas derivadas de taninos. Los demás compuestos químicos y moléculas, como se muestra en la Figura 4, no se consideraron antiincrustantes satisfactorios.

¿Qué organismos son inhibidos por productos naturales derivados de plantas terrestres? Entre los resultados obtenidos en los artículos, se identifican bacterias (microfouling) e invertebrados (macrofouling) como organismos objetivos para la inhibición. El 24\% de los resultados antiincrustantes satisfactorios se centraron en el microfouling (Xu, et al., 2005; Qian, et al., 2010; Salta, et al., 2013; Pérez, et al., 2014; Nandhini y Revathi, 2016; Moodie, et al., 2018; Agostini, et al., 2019; 2020; Nadir, et al., 2020), el 61\% en el macrofouling (Takasawa, et al., 1990; Etoh, et al., 2002; Stupak, et al., 2003; Goransson, et al., 2004; Angarano, et al., 2007; Pérez, et al., 2007; Feng, et al., 2009; Zhou, et al., 2009; Qian, et al., 2010; Bellotti, et al., 2014; Cui, et al., 2014; Huang, et al., 2014; Pérez, et al., 2014; Bogdan, et al., 2018; Feng, et al., 2018; Clasen y Kesel, 2019), y el 14\% en ambas comunidades. En el Anexo 2 se presenta la lista de organismos inhibidos por la acción de extractos, compuestos o moléculas derivadas de plantas terrestres.

Las características de las plantas terrestres que condujeron a la actividad antiincrustante fueron diferentes entre el microfouling y macrofouling (Figura 5). La inhibición del microfouling está más asociada con los compuestos Juglone, Ciclotida, Ácido zostérico, Terpeno, Ácido secochiliolide y Cannabinoide; a las hojas, frutos, tallos y raíces; y a las familias Turmeraceae, Sapotaceae, 
Rhyzophoraceae, Juglandaceae, Solanaceae, Acanthaceae, Fabbaceae, Cannabaceae, Pinaceae y Combretaceae. Mientras que la inhibición de macrofouling está más relacionada con los compuestos Flavonoide, Alcaloide, Ácido graso, Floroglucinol, Isotiocionato, Fenole, Tanino, Estibenoide; a la semilla; y a familias Rutaceae, Violanaceae, Anacardiaceae, Arecaceae, Zingeberaceae, Apiaceae, Covolvulaceae, Piperaceae, Myrtaceae, Papaveraceae, Nyssaceae, Fagaceae, Menispermaceae y Sapindaceae. Esta diferencia probablemente se deba al hecho de que la mayoría de los estudios ha evaluado los tratamientos solo para una de las comunidades (micro o macrofouling). Solo un estudio evaluó los efectos antiincrustantes considerando micro y macrofouling (Pérez, et al., 2014). Estos autores realizaron las pruebas in situ en Mar del Plata (Argentina), en el verano de 2008. Los resultados indicaron que las pinturas a base de ácido secochiliolide inhibieron por completo el asentamiento de invertebrados y macroalgas. Además, se registró una menor densidad y diversidad de especies de microfouling. En la Figura 5 también es posible observar que tanto las bacterias y microalgas (microfouling) como las macroalgas e invertebrados (macrofouling) presentaron diferentes relaciones con las características inhibitorias de las plantas terrestres, que pueden explicarse porque la mayoría de los estudios ha evaluado los tratamientos solo para un grupo de organismos.

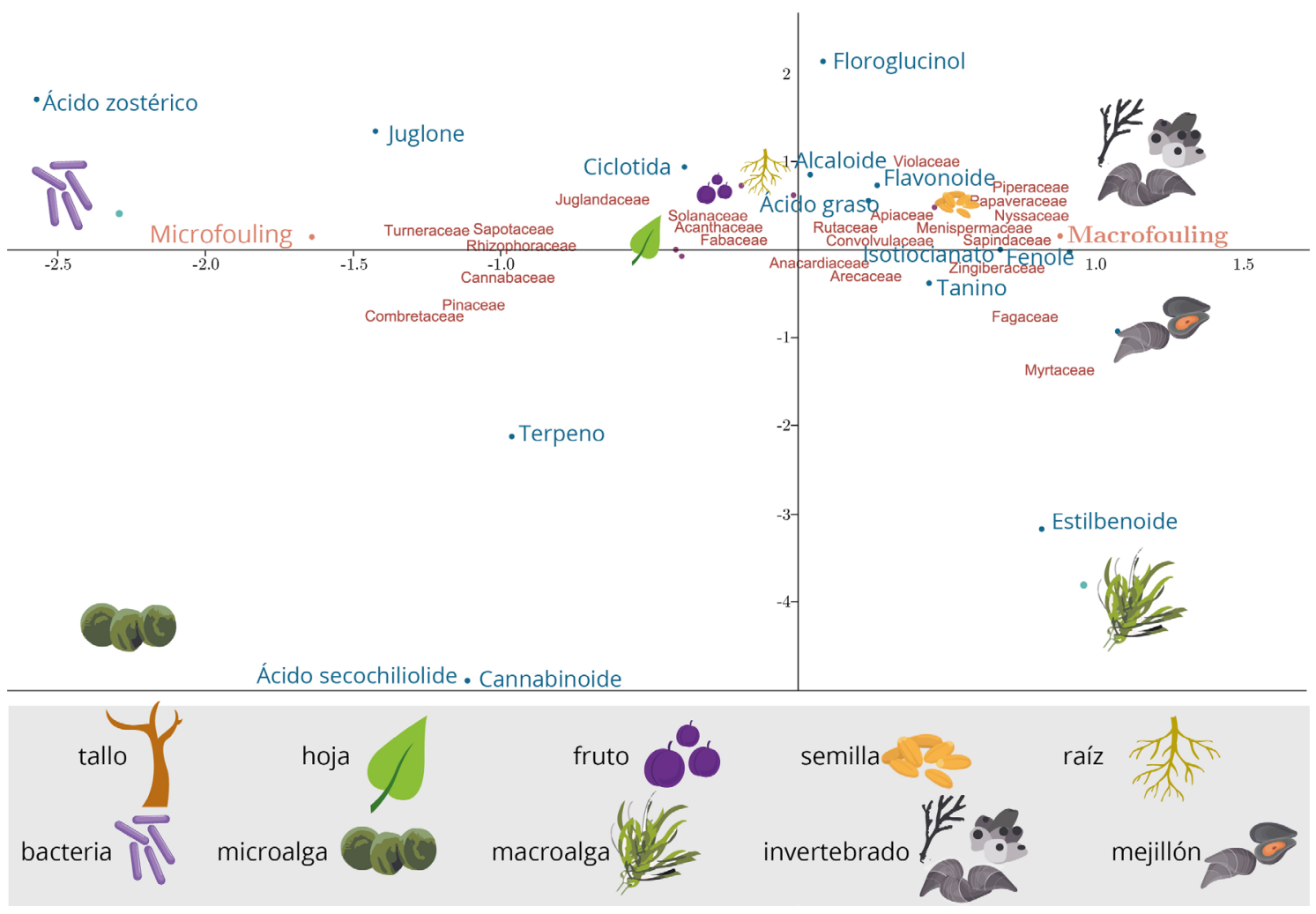

Figura 5. Análisis de correspondencia ordenando las familias, las partes y los compuestos químicos de las plantas terrestres que presentaron datos 
antiincrustantes satisfactorios en relación con el tipo de comunidad (explicación de los primeros dos ejes $=25 \%$ ).

\section{Microfouling}

La mayoría de los estudios (98\%) evaluó los tratamientos contra una comunidad bacteriana en lugar de una bacteria aislada. Los biofilms naturales consisten en un consorcio de especies que se influyen entre sí de manera sinérgica y antagónica (Pichlmaier, et al., 2008; Macedo y Abraham, 2009). Los ensayos de microfouling pueden realizarse con muchas bacterias de biofilm en varios filamentos y géneros, distribuidos geográficamente en todo el mundo (Lee, et al., 2008; Leary, et al., 2014; Muthusamy, et al., 2017). Por ejemplo, las bacterias gram negativas representan la composición bacteriana de biofilm heterotrófica que se encuentra en las estructuras hechas por el hombre en todo el mundo (Gupta, 2000; Muthusamy, et al., 2017).

Además de eso, es necesario evaluar si la actividad antiincrustante es antibiofilm o antibiótico. Aunque las actividades antibacterianas y de antibiofilm reflejan una inhibición bacteriana marina, el efecto antibiofilm es más interesante ya que no elimina las bacterias planctónicas, evitando la colonización del sustrato y, lo que es más importante, no impone presión sobre las bacterias para la adquisición de resistencia (Agostini, et al., 2020).

Según Agostini y otros $(2017,2018)$, la formación de biofilms bacterianos se considera un requisito previo para las incrustaciones de algas e invertebrados. Los factores que influyen en el asentamiento de invertebrados en sustratos duros aún no se conocen bien. Sin embargo, estudios recientes han demostrado que los biofilms bacterianos podrían ser el desencadenante necesario para la sucesión ecológica en superficies de sustrato duro sumergidas en el medio acuático (Agostini, et al., 2017; 2018; Freckelton, et al., 2017). Esto se debe a que el modelo de facilitación supone que sólo ciertas especies de "sucesión temprana" pueden colonizar el sustrato virgen debido a sus características específicas. Estos primeros colonos modifican el entorno para hacerlo más adecuado para otras especies de "sucesión tardía" (Jenkins y Martins, 2010). De esta manera, los resultados observados como positivos en cuanto a la inhibición de microfouling pueden aplicarse a macrofouling.

\section{Macrofouling}

La mayoría de los estudios (83\%) evaluó los tratamientos contra una comunidad de invertebrados en lugar de algas, principalmente contra artrópodos, poliquetos y moluscos. La inhibición de mejillones está más relacionada con los compuestos Isotiocianato, Fenole y Tanino, y con las familias Zingeberaceae, Myrtaceae y Fagaceae. Ningún trabajo incluido en esta revisión ha 
evaluado los efectos de los tratamientos sobre la inhibición del mejillón dorado. Sin embargo, algunos estudios mostraron resultados positivos para otras especies de mejillones (Takasawa, et al., 1990; Etoh, et al., 2002; Angarano, et al., 2007). Takasawa y otros (1990) aplicaron glucósido de kaempferol acilado, un flavonoide, aislado de hojas de Quercus dentata (Fagaceae) y raponticinas aciladas, un estilbenoide, de hojas de Eucalyptus rubida (Myrtaceae) como sustancias activas, realizando ensayos con Mytilus edulis (mejillón azul). Como estos compuestos contienen grupos fenólicos, repelió el asentamiento. Etoh y otros (2002) probaron que trans-6-, 8-, and 10-shogaols (alcaloide) de un extracto de las raíces de jengibre, Zingiber occinale (Zingiberaceae), mostraron la actividad antiincrustante más alta contra Mytilus edulis. Mientras Angarano y otros (2007) evaluaron la capsaicina de productos naturales derivados de plantas por su potencial para inhibir la fijación del biso de Dreissena polymorpha (mejillón cebra). Esta prueba reveló que la capsaicina (8-methyl-Nvanillyl-trans-6nonenamide), un alcaloide, inhibió la fijación del biso, siendo considerado un producto prometedor.

Cabe señalar que, a pesar de los resultados satisfactorios de inhibición de la bioincrustación, menos de la mitad (48\%) de los tratamientos evaluó la toxicidad potencial de productos derivados de plantas terrestres. Por un lado, algunos autores garantizan la ausencia de toxicidad (Angarano, et al., 2007); por otro lado, hay evidencia en la literatura sobre posibles efectos fisiológicos de compuestos vegetales en mamíferos (Ekiert y Kisiel, 1997); por lo tanto, los tratamientos deben ser probados y evaluados previamente para encontrar la mejor dosis-respuesta, utilizando especies sensibles de varios niveles tróficos.

De acuerdo con Ralston y Swain (2009), además de la no toxicidad, las nuevas alternativas químicas antiincrustantes deben centrarse en los siguientes parámetros: permitir al menos cinco años de control de bioincrustación; ser duraderas, resistentes a los daños y reparables; ser rentables y de bajo mantenimiento; ser fáciles de aplicar; y eficaces, sin y con flujo. Además, se debería incorporar como parámetro que la alternativa química debe ser amigable con el medio ambiente.

\section{CONCLUSIONES}

Los productos naturales derivados de plantas terrestres tienen un gran potencial como antiincrustantes sostenibles, inhibiendo la colonización de bacterias, microalgas, macroalgas e invertebrados. Sin embargo, se deben realizar más estudios, siempre dirigidos a la comunidad bioincrustante en su conjunto y con pruebas ecotoxicológicas apropiadas. Las plantas terrestres de las familias Fabaceae, Anacardiaceae, Arecaceae, Zingiberaceae y Rutaceae, así como los extractos hechos de hojas, frutos y semillas, tienen el mayor potencial antiincrustante. Con respecto a la inhibición específica de los mejillones, los 
compuestos alcaloides y flavonoides ya han mostrado resultados prometedores, derivados de las familias Zingeberaceae, Myrtaceae y Fagaceae. En tanto, se identifica la ausencia de estudios relacionados con el uso de este tipo de anitiiincrustantes para el biofouling ocasionado específicamente por el mejillón dorado.

\section{AGRADECIMIENTOS}

Los autores pertenecen a un grupo de trabajo interinstitucional e interdisciplinario con potencial de trabajo en distintas escalas y en diversidad de ambientes acuáticos en Brasil y Uruguay. Agradecen a la Universidade Federal do Rio Grande (FURG), la Universidade Federal do Rio Grande do Sul (UFRGS), al Laboratorio Tecnológico del Uruguay (LATU), a Latitud-Fundación LATU y a la Facultad de Ciencias, Universidad de la República (Udelar).

\section{REFERENCIAS}

Agostini, V.O., Ritter, M.N., Macedo, A.J. Muxagata, E. y Erthal, F., 2017. What determines sclerobiont colonization on marine mollusk shells? En: PLoS ONE, 12, e0184745. https://doi.org/10.1371/journal.pone.0184745

Agostini, V.O., Macedo, A.J. y Muxagata, E., 2018. O papel do biofilme bacteriano no acoplamento bento-pelágico, durante o processo de bioincrustação. En: Revista Liberato, 19(31), pp.1-134. https://doi.org/10.31514/rliberato.2018v19n31.p23

Agostini, V.O., Macedo, A.J. Muxagata, E. Silva, M.V.da y Pinho, G.L.L., 2019. Natural and non-toxic products from Fabaceae Brazilian plants as a replacement for traditional antifouling biocides: an inhibition potential against initial biofouling. En: Environmental Science and Pollution Research, 26, pp.27112-27127 https://doi.org/10.1007/s11356-019-05744-4

Agostini, V.O., Macedo, A.J. Muxagata, E. Silva, M.V.da y Pinho, G.L.L., 2020. Nontoxic antifouling potential of Caatinga plant extracts: effective inhibition of marine initial biofouling. En: Hydrobiologia, 847, pp.45-60. https://doi.org/10.1007/s10750-019-04071-6

Amara, I., Miled, W., Slama, R.B. y Ladhari, N., 2018. Antifouling processes and toxicity effects of antifouling paints on marine environment. A review. En: Environmental Toxicology and Pharmacology, 57, pp.115-130. https://doi.org/10.1016/j.etap.2017.12.001 
Angarano, M-B., McMahon, R.F., Hawkins, D.L. y Schetz, J.A., 2007. Exploration of structure-antifouling relationships of capsaicin-like compounds that inhibit zebra mussel (Dreissena polymorpha) macrofouling. Biofouling: En: The Journal of Bioadhesion and Biofilm Research, 23(5), pp.295-305. https://doi.org/10.1080/08927010701371439

Agra, M.F., Freitas, P.F. y Barbosa-Filho, J.M., 2007. Synopsis of the plants known as medicinal and poisonous in Northeast of Brazil. En: Brazilian Journal of Pharmacognosy, 17, pp.114-140. https://doi.org/10.1590/S0102695X2007000100021

Appezzato-da-Glória, B. y Carmello-Guerreiro, S.M., 2006. Anatomia vegetal. 2a ed. Viçosa: Editora UFV. 430 p.

Azis, P.K.A., Al-Tisan, I. y Sasikumar, N., 2001.Biofouling potential and environmental factors of seawater at a desalination plant intake. En: Desalination, 135, pp.69-82. https://doi.org/10.1016/S00119164(01)00140-0

Bellotti, N., Amo, B. y Romagnoli, R., 2014. Assessment of tannin antifouling coatings by scanning electronmicroscopy. En: Progress in Organic Coatings, 77, pp.1400-1407. https://doi.org/10.1016/j.porgcoat.2014.05.004

Bogdan, S., Deya, C., Micheloni, O., Bellotti, N. y Romagnoli, R. Natural products to control biofilm on painted surfaces. En: Pigment \& Resin Technology, 47(2), pp.180-187. https://doi.org/10.1108/PRT-01-2017-0004

Boltovskoy, D. y Correa, C., 2015. Ecosystem impacts of the invasive bivalve Limnopernafortunei (golden mussel) in South America. En: Hydrobiologia, 746, pp.81-95. https://doi.org/10.1007/s10750-014-1882-9

Boy, H.I.A, Rutilla, A.J.H., Santos, K.A., Ty, A.M.T., Yu, A.I., Mahboob, T., Tangpoong, J. y Nissapatorn, V., 2018. Recommended medicinal plants as source of natural products: a review. En: Digital Chinese Medicine, 1(2), pp.131-142. https://doi.org/10.1016/S2589-3777(19)30018-7

Breitig, G., 1965. The use of ultrasound in the eradication of larvae. Greiswald: University Greiswald. (Tesis de doctorado).

Buchanan, R.B., Gruissem, W. y Jones, R.L., 2000. Biochemistry and molecular biology of plants. Rockville: American Society of Plant Physiologists. 1280 p. 
Cabral, R.S., Sartori, M.C., Cordeiro, I., Queiroga, C.L., Eberlin, M.N., Lago, J.H.G., Moreno, P.R.H. y Young, M.C.M., 2012. Anticholinesterase activity evaluation of alkaloids and coumarin from the stems of Conchocarpusfontanesianus. En: Brazilian Journal of Pharmacognosy, 22(2), pp.374-380. https://doi.org/10.1590/S0102-695X2011005000219

Cho, J.Y., Kwon, E.-H., Choi, J.-S., Hong, S.-Y., Shin, H.-W. y Hong, Y.-K., 2001. Antifouling activity of seaweed extracts on the green alga Enteromorpha prolifera and the mussel Mytilus edulis. En: Journal of Applied Phycology, 13(2), pp.117-125. https://doi.org/10.1023/A:1011139910212

Clasen, A. y Kesel, A.B., 2019. Microstructural surface properties of drifting seeds-a model for non-toxic antifouling solutions. En: Biomimetics, 4, 37. https://doi.org/10.3390/biomimetics4020037

Cordell, G., 1981. Introduction to alkaloids: a biogenetic approach. Nueva York: Wiley and Sons. 1055 pp.

Correia, S.de J., David, J.P. y David, J.M., 2006. Metabólitos secundários de espécies de Anacardiaceae. En: Quimica Nova, 6, pp.1287-1300. https://doi.org/10.1590/S0100-40422006000600026

Cseke, L.J., Kirakosyan, A., Kaufman, P.B., Warber, S.L., Duke, J.A., Brielmann, H.L., 2006. Natural products from plants. $2^{\mathrm{a}}$ ed. Boca Ratón: CRC Press. 569 p.

Cui, Y.T., Teo, S.L.M., Leong, W. y Chai, C.L.L., 2014. Searching for "Environmentally-Benign" antifouling biocides. En: International Journal of Molecular Sciences, 15, pp.9255-9284. https://doi.org/10.3390/ijms15069255

Dahms, H.U. y Dobretsov, S., 2017. Antifouling compounds from marine macroalgae. En: Marine Drugs, 15(9), pp.265. https://doi.org/10.3390/md15090265

Desai, D.V., 2008. Impact of Irgarol 1051 on the larval development and metamorphosis of Balanus amphitrite Darwin, the diatom Amphora coffeaformis and natural biofilm. En: Biofouling: The Journal of Bioadhesion and Biofilm Research, 24(5), pp.393-403. https://doi.org/10.1080/08927010802339764

Devi, P., Solimabi, W., D'Souza, L., Sonak, S., Kamat, S.Y. y Singbai, S.Y.S., 1997. Screening of some marine plants for activity against marine fouling bacteria. En: Botanica Marina, 40, pp.87-91. https://doi.org/10.1515/botm.1997.40.1-6.87 
Di Stasi, L.C. y Hiruma-Lima, C.A., 2002. Plantas medicinais na Amazônia e na Mata Atlântica. 2. San Pablo: São Paulo. 608 p.

Dobretsov, S. y Rittschof, D., 2020. Love at first taste: induction of larval settlement by marine microbes. En: International Journal of Molecular Sciences, 21(3), pp.731.https://doi.org/10.3390/ijms21030731

Ekiert, H. y Kisiel, W., 1997. Coumarins and alkaloids in shoot culture of Ruta graveolens. En: Acta Societatis Botanicorum Poloniae, 66(3-4), pp.329-332. https://doi.org/10.5586/asbp.1997.039

Etoh, H., Kondoh, T., Noda, R., Singh, I.P., Sekiwa, Y., Morimitsu, K. y Kubota, K., 2002. Shogaols from Zingiber officinale as Promising Antifouling Agents. En: Bioscience, Biotechnology, and Biochemistry, 66(8), pp.1748-1750. https://doi.org/10.1271/bbb.66.1748

Feng, D.Q., Ke, C.H., Lu, C.Y. y Li, S.J., 2009. Herbal plants as a promising source of natural antifoulants: evidence from barnacle settlement inhibition. En: Biofouling: The Journal of Bioadhesion and Biofilm Research, 25(3), pp.181190, https://doi.org/10.1080/08927010802669210

Feng, D.Q., He, J., Chen, S.Y., Su, P., Ke, P.H. y Wang, W., 2018. The plant alkaloid camptothecin as a novel antifouling compound for marine paints: laboratory bioassays and field Trials. En: Marine Biotechnology, 20(5), pp.623-638. https://doi.org/10.1007/s10126-018-9834-4

Fernández-Niño M, e Islam Z., 2017.The potential of synthetic biology for improving environmental quality and human health in developing countries. En: Salud UIS, 49(1), pp.10 p.

Freckelton, M.-L., Nedved, B.T. y Hadfield, M.G., 2017. Induction of invertebrate larval settlement; different bacteria, different mechanisms? En: Scientific Reports, 7, pp.42557. https://doi.org/10.1038/srep42557

Fujita, D.S., Takeda, A.M., Coutinho, R. y Fernandes, F.C., 2015. Influence of antifouling paint on freshwater invertebrates (Mytilidae, Chironomidae and Naididae): Density, richness and composition. En: Brazilian Journal of Biology, 75(4), suppl. 1, pp.S70-S78. https://doi.org/10.1590/15196984.05114 
Giulietti, A.M., Harley, R.M., Queiroz, L.P., Wanderley, M.G. y Berg, C.V.B., 2005. Biodiversidade e conservação das plantas no Brasil [En línea]. En: Megadiversidade, 1, pp.52-60. [Consulta: abril de 2020]. Disponible en:http://www.agencia.cnptia.embrapa.br/Repositorio/BIOD_ConservacaoI D-eWNPNpKEJw.pdf

Gopikrishnan, V., Radhakrishnan, M., Pazhanimurugan, R., Shanmugasundaram, T. y Balagurunathan, R., 2015. Bioprospecting of actinobacteria from mangrove and estuarine sediments for antifouling compounds [En línea]. En: Journal of Chemical and Pharmaceutical Research, 7(7), pp.1144-1153. [Consulta: abril de 2020]. Disponible en: https://www.researchgate.net/publication/287509924_Bioprospecting_of_ marine_derived_actinomycetes_with_special_reference_to_antimycobacteria I_activity

Goransson, U., Sjogren, M., Svangard, E., Claeson, P. y Bohlin, L., 2004. Reversible antifouling effect of the cyclotide cycloviolacin $\mathrm{O} 2$ against barnacles. En: Journal of Natural Products, 67, pp.1287-1290. https://doi.org/10.1021/np0499719

Gupta, R.S., 2000. The phylogeny of proteobacteria: relationships to other eubacterial phyla and eukaryotes. En: FEMS Microbiology Reviews, 24, pp.367-402. https://doi.org/10.1111/j.1574-6976.2000.tb00547.x

Hagerman, A.E. y Butler, L.G., 1989. Choosing appropriate methods and standards for assaying tannin [En línea]. En: Journal of Chemical Ecology, 15, pp.1795-1810. [Consulta: abril de 2020]. Disponible en: https://link.springer.com/article/10.1007/BF01012267

Hammer, Ø. y Harper, D.A.T., 2006. Paleontological Data. PAST: Paleontological Statistics Software Package for Education and Data Analysis [En línea]. Version 2.17c. [s.I]: [s.n.]. [Consulta: abril de 2020]. Disponible en: http://priede.bf.lu.lv/ftp/pub/TIS/datu_analiize/PAST/2.17c/download.html

Huang, X-Z., Xu, Y., Zhang, Y-F., Zhang, Y., Wong, H., Han, Z., Yin, Y. y Qian, P-Y., 2014. Nontoxic piperamides and their synthetic analogues as novel antifouling reagentes. En: Biofouling: The Journal of Bioadhesion and Biofilm Research, 30(4), pp.473-481. https://doi.org/10.1080/08927014.2014.889688

Holtum, R.E., 1950. The Zingiberaceae of the Malay peninsula. En: The Gardens' Bulletin, Singapore, 13(4), pp.1-50. 
Jenkins, S.R. y Martins, G.M., 2010. Succession on hard substrata. En: Durr, S. y Thomason, J.C., eds. Biofouling. Oxford: Wiley. 456 p.

Karasawa, M.M.G. y Mohan, C., 2018. Fruits as prospective reserves of bioactive compounds: a review. En: Natural Products and Bioprospecting, 8, pp.335346. https://doi.org/10.1007/s13659-018-0186-6

Katsuyama, I., Satuito, C.G., Maeda, T., Oonishi, M. yKumagai, T., 2005. The effect of DC-pulse electric stimulus on the swimming behavior of larvae of the freshwater mussel Limnopernafortuneiin flowing water within a pipe. En: Sessile Organisms, 2, pp.1-5. https://doi.org/10.4282/sosj.22.1

Kothari, V. y Seshadri, S., 2010. Antioxidant activity of seed extracts of Annona squamosa and Carica papaya. En: Nutrition \& Food Science, 40(4), pp.403408. https://doi.org/10.1108/00346651011062050

Konstantinou, I.K. y Albanis, T.A., 2004. Worldwide occurrence and effects of antifouling paint booster biocides in the aquatic environment: a review. En: Environment International, 30, pp.235-248. https://doi.org/10.1016/S01604120(03)00176-4

Leary, D.H., Li, R.W., Hamdan, L.J., Hervey, I.V.W.J., Lebedev, N., Wang, Z., Deschamps, J.R., Kusterbeck, A.W. y Vora, G.J., 2014. Integrated metagenomic and metaproteomic analyses of marine biofilm communities. En: Biofouling: The Journal of Bioadhesion and Biofilm Research, 30(10), pp.1211-1223. https://doi.org/10.1080/08927014.2014.977267

Lee, J.W., Nam, J.H., Kim, Y.H., Lee, K.H. y Lee, D.H., 2008. Bacterial communities in the initial stage of marine biofilm formation on artificial surfaces. En: Journal of Microbiology, 46(2), pp.174-182. https://doi.org/10.1007/s12275008-0032-3

Liu, R.H., 2004. Potential synergy of phytochemicals in cancer prevention: mechanism of action. En: The Journal of Nutrition, 134(12), pp.3479S3485S. https://doi.org/10.1093/jn/134.12.3479S

Liu, Y., Shao, X., Huang, J. y Li, H., 2019. Flame sprayed environmentally friendly high-density polyethylene. En: Hydrobiologia, 847, pp.45-60. https://doi.org/10.1016/j.matlet.2018.11.144

Macedo, A.J. y Abraham, W.R., 2009. Can infectious biofilm be controlled by blocking bacterial communication? En: Journal of Medicinal Chemistry, 5(6), pp.517-528. https://doi.org/10.2174/157340609790170515 
Malafaia, C.B., Jardelino, A.C.S., Silva, A.G.S., Souza, E.B., Macedo, A.J., Correia, M.T.S. y Silva, M.V., 2017. Effects of Caatinga plant extracts in planktonic growth and biofilm formation in Ralstonia solanacearum. En: Microbial Ecology, 75(3), pp.555-561. https://doi.org/10.1007/s00248-017-1073-0

Manilal, A., Sujith, S., Sabarathnam, B., Seghal Kiran, G., Selvin, J., Shakir, C. y Lipton, A.P., 2010. Antifouling potentials of seaweeds collected from the Southwest Coast of India [En línea]. En: World Journal of Agricultural Sciences, 6(3), pp.243-248. [Consulta: abril de 2020]. Disponible en: http://citeseerx.ist.psu.edu/viewdoc/download?doi=10.1.1.415.4820\&rep=r ep1\&type $=p$

Maranhão, R.A. y Stori, N., 2019. Estratégias de gestão ambiental adotadas pelo setor elétrico para controle do Limnoperna fortunei [En línea]. En: Brazillian mJournal of Business, 1(4), pp.1605-1613. [Consulta: abril de 2020]. Disponible en: https://www.brazilianjournals.com/index.php/BJB/article/view/4223/0

Maréchal, J-F. y Hellio, C., 2009. Challenges for the development of new nontoxic antifouling challenges for the development of new nontoxic antifouling solutions. En: International Journal of Molecular Sciences, 10, pp.4623-4637. https://doi.org/10.3390/ijms10114623

Medeiros-Costa, J.T., 2002. As espécies de plameiras (Arecaceae) do Estado de Pernambuco, Brasil. En: Tabarelli, M. y Silva, J.M.C, orgs. Diagnostico da biodiversidade de Pernambuco. v.1. Recife: SECTMA \& Massangana. pp.229-236

Moodie, L.W.K., Cervin, G., Trepos, R., Labriere, C., Hellio, C., Pavia, H. y Svenson, J., 2018. Design and biological evaluation of antifouling dihydrostilbene oxime hybrids. En: Marine Biotechnology, 20(2), pp.257-267. https://doi.org/10.1007/s10126-018-9802-z

Muthusamy, S., Lundin, D., Branca, R.M.M.M., Baltar, F., Gonzalez, J.M., Lehtio, J. y Pinhassi, J., 2017. Comparative proteomics reveals signature metabolisms of exponentially growing and stationary phase marine bacteria. En: Environmental Microbiology, 19(6), pp.2301-2319. https://doi.org/10.1111/1462-2920.13725

Nandakumar, K. y Yano, T., 2003. Biofouling and its prevention: a comprehensive overview. En: Biocontrol Science, 8(4), pp.133-144.

https://doi.org/10.4265/bio.8.133 
Nadir, I., Rana, N.F., Ahmad, N.M., Tanweer, T., Batool, A., Taimoor, Z., Riaz, S. y Ali, S.M., 2020. Cannabinoids and terpenes as an antibacterial and antibiofouling promotor for PES water filtration membranes. En: Molecules, 25(3), pp.691. https://doi.org/10.3390/molecules25030691

Nandhini, S. y Revathi, K., 2016. Antifouling activity of extracts from mangroves against biofouling bacteria isolated from boats in Royapuram, Chennai, India. En: International Journal of Current Microbiology and Applied Sciences, 5(8), pp.324-335. https://doi.org/10.20546/IJCMAS.2016.508.035

Omae, I., 2003. General aspects of tin-free antifouling paints. En: Chemical Reviews, 103, pp.3431-3448. https://doi.org/10.1021/cr030669z

Pancharoen, O., Prawat, U. y Tuntiwachwuttikul, P., 2000. Phytochemistry of the zingiberaceae. En: Studies in Natural Products Chemistry, 23, pp.797-865. https://doi.org/10.1016/s1572-5995(00)80142-8

Pell, S.K.; Mitchell, J.D., Miller, A.J. y Lobova, T.A., 2011. Anacardiaceae. En: KubtzkiI, K., ed. The families and genera of vascular plants. Flowering plants, Eudicots - Sapindales, Cucurbitales, Myrtaceae. V.10. Berlin: Springer Verlag. pp.7-50.

Pérez, M., García, M., Blustein, G. y Stupak, M., 2007. Tannin and tannate from the quebracho tree: an eco-friendly alternative for controlling marine biofouling. En: Biofouling: The Journal of Bioadhesion and Biofilm Research, 23(3), pp.151-159. https://doi.org/10.1080/08927010701189484

Pérez, M., García, M., Sánchez, M., Stupak, M., Mazzuca, M., Palermo, J.A. y Blustein, G., 2014. Effect of secochiliolide acid isolated from the Patagonian shrub Nardophyllumbryoides as active component in antifouling paints. En: International Biodeterioration \& Biodegradation, 89, pp.37e44. https://doi.org/10.1016/j.ibiod.2014.01.009

Pichlmaier, M., Marwitz, V., Ku“hn, C., Niehaus, M., Klein, G., Bara, C., Haverich, A. y Abraham, W.-R., 2008. High prevalence of asymptomatic bacterial colonization of rhythm management devices. En: Europace, 10, pp.10671072. https://doi.org/10.1093/europace/eun191

Prabhakaran, S., Rajaram, R., Balasubramanian, V. y Mathivanan, K., 2012. Antifouling potentials of extracts from seaweeds, seagrasses and mangroves against primary biofilmm forming bacteria. En: Asian Pacific Journal of Tropical Biomedicine, 2(1), pp.S316-S322. https://doi.org/10.1016/S2221-1691(12)60181-6 
Qian, P-Y., Xu, Y. y Fusetani, N., 2010. Natural products as antifouling compounds: recente progress and future perspectives. En: Biofouling: The Journal of Bioadhesion and Biofilm Research, 26(2), pp.223-234. https://doi.org/10.1080/08927010903470815

Ralston, E. y Swain, G., 2009. Bioinspiration-the solution for biofouling control? En: Bioinspiration and Biomimetics, 4, pp.015007. https://doi.org/10.1088/1748-3182/4/1/015007

Raven, P.H., Evert, R.F. y Eichhorn, S.E., 1992. Biologiavegetal. 5a ed. Nueva York: Worth Publishers. $876 \mathrm{p}$.

Salta, M., Wharton, J.A., Dennington, S.P., Stoodley, P. y Stokes, K.R., 2013. Antibiofilm performance of three natural products against initial bacterial attachment. En: International Journal of Molecular Sciences, 14(11), pp.21757-21780. https://doi.org/10.3390/ijms141121757

Sandjo, L.P., Kuete, V., Tchangna, R.S., Efferth, T. y Ngadjui, B.T., 2014. Cytotoxic Benzophenanthridine and Furoquinoline Alkaloids from Zanthoxylum buesgenii (Rutaceae). En: Chemistry Central Journal, 8(61), pp.4. https://doi.org/10.1186/s13065-014-0061-4

Santos, C.P., Vicenzi, J., Berutti, F.A., Mansur, M.C.D., Pérez Bergmann, C., Raya Rodriguez, M.T., Vilar Nehrke, M. y Leite Zurita, M.L., 2012. Controle de bivalves com a utilização do ultrassom. En: Mansur, M.C.D., Santos, C.P., Pereira, D., Padula, P.I.C., Leite, Z.M.L., Raya, R.M.T., Vilar, N.M. y Aydos, B.P.E., eds. Moluscos límnicos invasores no Brasil. Biologia, prevenção, controle. Porto Alegre: Redes Editora. pp.339-341.

Schultz, M.P., Bendick, J.A., Holm, E.R. y Hertel, W.M., 2011. Economic impact of biofouling on a naval surface ship. En: Biofouling: The Journal of Bioadhesion and Biofilm Research, 27(1), pp.87-98. https://doi.org/10.1080/08927014.2010.542809

Sichaem, J., Jirasirichote, A., Sapasuntikul, K., Khumkratok, S., Sawasdee, P., Do, T.M.L. y Tip-pyang, S., 2014. New furoquinoline alkaloids from the leaves of Evodia lepta. En: Fitoterapia, 92, pp.270-273. https://doi.org/10.1016/j.fitote.2013.12.002

Soroldoni, S., Abreu, F., Castro, I.B., Duarte, F.A. y Pinho, G.L.L., 2017. Are antifouling paint particles a continuous source of toxic chemicals to the marine environment? En: Journal of Hazardous Materials, 15(330), pp.7682. https://doi.org/10.1016/j.jhazmat.2017.02.001 
Stupak, M.E., García, M.T. y Pérez, M.C., 2003. Non-toxic alternative compounds for marine antifouling paints. En: International Biodeterioration \& Biodegradation, 52, pp.49-52. https://doi.org/10.1016/S09648305(03)00035-0

Takasawa, R., Etoh, H., Yagi, A., Sakata, K. e Ina, K., 1990. Nonylphenols as promising antifouling agents found by a simple bioassay method using the blue mussel, Mytilus edulis. En: Agricultural and Biological Chemistry, 54(6), pp.1607-1610. https://doi.org/10.1080/00021369.1990.10870144

Teixeira, V.L, 2010. Caracterização do estado da arte em biotecnologia marinha no Brasil [En línea]. Brasilia: Ministério da Saúde, Organização Panamericana da Saúde. Ministério da Ciência e Tecnologia. (Série B. Textos Básicos de Saúde). 134p. [Consulta: abril de 2020]. Disponible en: http://www.terrabrasilis.org.br/ecotecadigital/index.php/estantes/pesquisa /1731-caracterizacao-do-estado-da-arte-em-biotecnologia-marinha-nobrasil

Telegdi, J., Trif, L. y Romanszki, L., 2016. Smart anti-biofouling composite coatings for naval applications. En: Montemor, M.F., ed. Transport, structural, environmental and energy applications. Cambridge: Elsevier. (Woodhead Publishing Series in Composites Science and Engineering). https://doi.org/10.1016/B978-1-78242-283-9.00005-1

Trentin, D.S., Giordani, R.B., Zimmer, K.R., Silva, A.G., Silva, M.V., Correia, M.T.S., Baumvol, I.J.R. y Macedo, A.J., 2011. Potential of medicinal plants from the Brazilian semi-arid region (Caatinga) against Staphylococcus epidermidis planktonic and biofilm lifestyles. En: Journal of Ethnopharmacology, 137, pp.327-335. https://doi.org/10.1016/j.jep.2011.05.030

Uliano-Silva, M., Dondero, F., Dan Otto, T., Costa, I., Lima, N.C.B., Americo, J.A., Mazzoni, C.J., Prosdocimi, F. y Rebelo, M.F., 2018. A hybrid-hierarchical genome assembly strategy to sequence the invasive golden mussel, Limnopernafortunei. En: Giga Science, 7. https://doi.org/10.1093/gigascience/gix128

WHOI, Woods Hole Oceanographic Institution, 1952. Marine fouling and its prevention [En linea]. Annapolis: US Naval Institute. [Consulta: abril de 2020]. Disponible en: https://darchive.mblwhoilibrary.org/handle/1912/191

Williams, C.A. y Grayer, R.J., 2004. Anthocyanins and other flavonoids. En: Natural Product Reports, 21, pp.539-573. https://doi.org/10.1039/b311404j 
Xu, Q., Barrios, C.A., Cutright, T. y Newby, B.Z., 2005. Evaluation of toxicity of capsaicin and zosteric acid and their potential application as antifoulants. En: Environmental Toxicology, 20(5), pp.467-74. https://doi.org/10.1002/tox.20134

Zhou, X., Zhang, Z., Xu, Y., Jin, C., He, H., Hao, X. y Qian, P.-Y., 2009. Flavone and isoflavone derivatives of terrestrial plants as larval settlement inhibitors of the barnacle Balanus amphitrite. En: Biofouling: The Journal of Bioadhesion and Biofilm Research, 25(1), pp.69-76. https://doi.org/10.1080/08927010802455941 


\section{ANEXOS}

Anexo 1. Tratamientos probados con resultados satisfactorios sobre el uso de productos naturales de plantas terrestres como posible antiincrustante. *probados con microfouling, ** probados con macrofouling, *** probados con micro y macrofouling.

\begin{tabular}{|c|c|c|c|c|c|}
\hline Familia & Especies & $\begin{array}{l}\text { Parte de } \\
\text { la planta }\end{array}$ & Compuesto & Molécula & Autor \\
\hline Acanthaceae & Harpochilus neesianus & mezcla & & & \\
\hline \multirow{7}{*}{ Anacardiaceae } & $\begin{array}{l}\text { Myracrodruonurun } \\
\text { deuva }\end{array}$ & hojas & & & Agostini, et al. (2020)* \\
\hline & \multirow{2}{*}{ Schinopsi ssp. } & \multirow{2}{*}{ no informada } & tanino & & \multirow{2}{*}{ Pérez, et al. (2007)** } \\
\hline & & & tanino & & \\
\hline & \multirow{4}{*}{ no informada } & \multirow{4}{*}{ no informada } & $\operatorname{tanino}$ & & Bellotti, et al. (2014)** \\
\hline & & & tanino & & \multirow{2}{*}{ Qian, et al. (2010)*** } \\
\hline & & & tanino & & \\
\hline & & & tanino & & Stupak, et al. (2003)** \\
\hline Apiaceae & Apium graveolens & no informada & flavonoide & Apigenina $\left(\mathrm{C}_{15} \mathrm{H}_{10} \mathrm{O}_{5}\right)$ & Zhou, et al. (2009)** \\
\hline \multirow{6}{*}{ Arecaceae } & Acrocomiatotai & semillas & & & \multirow{5}{*}{ Clasen y Kesel (2019)** } \\
\hline & $\begin{array}{c}\text { Archontophoenix } \\
\text { myolensis }\end{array}$ & semillas & & & \\
\hline & $\begin{array}{c}\text { Coccothrinax } \\
\text { borhidiana }\end{array}$ & semillas & & & \\
\hline & Dypsis paludosa & semillas & & & \\
\hline & Licuala spinosa & semillas & & & \\
\hline & Nardophyllum bryoides & aérea & $\begin{array}{c}\text { ácido } \\
\text { secocoliolide }\end{array}$ & & Pérez, et al. (2014) \\
\hline Cannabaceae & Cannabis sativa & no informada & $\begin{array}{l}\text { cannabinoide } \\
\text { + terpeno }\end{array}$ & & Nadir, et al. (2020)* \\
\hline Combretaceae & Combretum caffrum & no informada & terpeno & Sesquiterpeno $\left(\mathrm{C}_{17} \mathrm{H}_{20} \mathrm{NaO}_{4}\right)$ & Moodie, et al. (2018)* \\
\hline \multirow[t]{6}{*}{ Convolvulaceae } & Ipomoea alba & semillas & & & Clasen y Kesel $(2019)^{\star * *}$ \\
\hline & Anadenanthera & frutas & & & \multirow{2}{*}{ Agostini, et al. (2019)* } \\
\hline & Apuleia leiocarpa & hojas & & & \\
\hline & Arachis hypogaea & no informada & flavonoide & Luteolina $\left(\mathrm{C}_{15} \mathrm{H}_{10} \mathrm{O}_{6}\right)$ & Zhou, et al. (2009) \\
\hline & Dioclea grandiflora & hojas & & & Agostini, et al. (2019)* \\
\hline & Erythrina berteroana & semillas & & & Clasen y Kesel (2019)** \\
\hline Fabaceae & Genista tinctoria & no informada & flavonoide & Genistein $\left(\mathrm{C}_{15} \mathrm{H}_{10} \mathrm{O}_{5}\right)$ & Zhou, et al. (2009)** \\
\hline
\end{tabular}

Continúa 


\begin{tabular}{|c|c|c|c|c|c|}
\hline Familia & Especies & $\begin{array}{l}\text { Parte de } \\
\text { la planta }\end{array}$ & Compuesto & Molécula & Autor \\
\hline & Myroxylon peruiferum & hojas & & & Agostini, et al. (2019)* \\
\hline & \multirow{4}{*}{ Sophora flavescens } & frutas & flavonoide & $\begin{array}{c}\text { Metoxkurarinona } \\
\text { (20-methoxykurarinone) }\end{array}$ & Feng, et al. (2009)** \\
\hline & & \multirow{3}{*}{ no informada } & flavonoide & 2'-methoxykurarinone matrine & \multirow{2}{*}{ 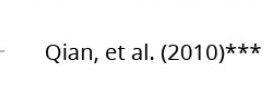 } \\
\hline & & & & & \\
\hline & & & tanino & & Stupak, et al. (2003)** \\
\hline \multirow[t]{2}{*}{ Fagaceae } & Quercus dentata & hojas & flavonoide & $\begin{array}{c}\text { Glucósido de } \\
\text { kaempferolacilado (kaempferol- } \\
\text { 3-O-a-L-(2",3"-di E- p-couma } \\
\text { royl)-rhamnoside) }\end{array}$ & Takasawa, et al. (1990)** \\
\hline & no informada & no informada & tanino & & Stupak, et al. (2003)** \\
\hline Juglandaceae & Juglans nigra & mezcla & juglone & Juglone $\left(\mathrm{C}_{10} \mathrm{H}_{10} \mathrm{O}_{3}\right)$ & Salta, et al. (2013)* \\
\hline \multirow{2}{*}{ Menispermaceae } & Stephania cepharantha & \multirow{2}{*}{ no informada } & alcaloide & Cepharanthine $\left(\mathrm{C}_{37} \mathrm{H}_{38} \mathrm{~N}_{2} \mathrm{O}_{6}\right)$ & \multirow{2}{*}{ Feng, et al. (2018)** } \\
\hline & Stephania tetrandra & & alcaloide & Tetrandrina $\left(\mathrm{C}_{38} \mathrm{H}_{42} \mathrm{~N}_{2} \mathrm{O}_{6}\right)$ & \\
\hline Myrtaceae & Eucalyptus rubida & hojas & estilbenoide & Raponticinaacilada $\left(\mathrm{C}_{21} \mathrm{H}_{24} \mathrm{O}_{9}\right)$ & Takasawa, et al. (1990)** \\
\hline Nyssaceae & $\begin{array}{l}\text { Camptotheca } \\
\text { acuminata }\end{array}$ & \multirow{4}{*}{ no informada } & alcaloide & $\begin{array}{l}\text { Camptotecina } \\
\left(\mathrm{C}_{20} \mathrm{H}_{16} \mathrm{~N}_{2} \mathrm{O}_{4}\right)\end{array}$ & \multirow[t]{2}{*}{ Feng, et al. (2018)** } \\
\hline Papaveraceae & Dicentra spectabilis & & alcaloide & Dicentrina $\left(\mathrm{C}_{20} \mathrm{H}_{21} \mathrm{NO}_{4}\right)$ & \\
\hline Pinaceae & Pinus armandii & & & $\mathrm{C}_{16} \mathrm{H}_{19} \mathrm{O}_{2}$ & Moodie, et al. (2018)* \\
\hline Piperaceae & Piper betle & & alcaloide & Piperoleina $\mathrm{B}\left(\mathrm{C}_{21} \mathrm{H}_{29} \mathrm{NO}_{3}\right)$ & Huang, et al. (2014)** \\
\hline \multirow[t]{2}{*}{ Rhizophoraceae } & Bruguiera cylindrica & hojas & & & \multirow{2}{*}{ Nandhini y Revathi (2016)* } \\
\hline & Rhizophora apiculata & hojas & & & \\
\hline \multirow{3}{*}{ Rutaceae } & \multirow{3}{*}{$\begin{array}{l}\text { Micromelum } \\
\text { integerrinum }\end{array}$} & \multirow{3}{*}{ no informada } & flavonoide & Calicopterina $\left(\mathrm{C}_{19} \mathrm{H}_{18} \mathrm{O}_{8}\right)$ & \multirow{3}{*}{ Zhou, et al. (2009)** } \\
\hline & & & flavonoide & Casticina $\left(\mathrm{C}_{19} \mathrm{H}_{18} \mathrm{O}_{8}\right)$ & \\
\hline & & & flavonoide & $\begin{array}{l}\text { 5,40-dihydroxy-3,6,7-trimethoxy } \\
\text { flavone }\end{array}$ & \\
\hline Sapindaceae & Sapindus saponaria & semillas & & & Clasen y Kesel $(2019)^{\star \star}$ \\
\hline \multirow{2}{*}{ Sapotaceae } & Manilka rarufula & hojas & & & \multirow{2}{*}{ Agostini, et al. (2020* } \\
\hline & Sideroxylon obtusifolium & corteza de tallo & & & \\
\hline Solanaceae & Nicotiana longiflora & mezcla & & & Bogdan, et al. (2018)** \\
\hline Turneraceae & Turnera hermannioides & hojas & & & Agostini, et al. (2020)* \\
\hline
\end{tabular}

Continúa 


\begin{tabular}{|c|c|c|c|c|c|}
\hline Familia & Especies & $\begin{array}{l}\text { Parte de } \\
\text { la planta }\end{array}$ & Compuesto & Molécula & Autor \\
\hline Violaceae & Viola odorata & \multirow{3}{*}{ no informada } & ciclotida & Cicloviolacina $\mathrm{O}_{2}$ & Goransson, et al. (2004)** \\
\hline \multirow{3}{*}{ Zingiberaceae } & Eucalyptus spp. & & & & \\
\hline & Tasmannia lanceolata & & terpeno & Sesquiterpeno $\left(\mathrm{C}_{17} \mathrm{H}_{20} \mathrm{NaO}_{4}\right)$ & \multirow[t]{2}{*}{ Etoh, et al. (2002)** } \\
\hline & Zingiber occinale & raíces & fenole & Shogaol (Trans-8-shogaol) & \\
\hline \multirow{12}{*}{ no informada } & \multirow{12}{*}{ no informada } & \multirow{12}{*}{ no informada } & alcaloide & Capsaicina $\left(\mathrm{C}_{18} \mathrm{H}_{27} \mathrm{NO}_{3}\right)$ & \\
\hline & & & flavonoide & $\begin{array}{c}\text { Penduletina (5,4'-dihy } \\
\text { droxy-3,6,7-trimethoxy flavone) }\end{array}$ & Cui, et al. (2014)** \\
\hline & & & alcaloide & $\begin{array}{c}\text { Capsaicina (8-methyl-N-vanillyl- } \\
\text { trans-6-nonenamide) }\end{array}$ & Angarano, et al. (2007) $)^{\star \star}$ \\
\hline & & & ciclotida & Cycloviolacin $\mathrm{O}_{2}$ & \multirow{6}{*}{ Qian, et al. (2010)*** } \\
\hline & & & alcaloide & Capsaicina $\left(\mathrm{C}_{18} \mathrm{H}_{27} \mathrm{NO}_{3}\right)$ & \\
\hline & & & alcaloide & $\begin{array}{l}\text { Capsaicina (N-vanillylnonamide } \\
\left.\qquad\left(\mathrm{C}_{17} \mathrm{H}_{27} \mathrm{NO}_{3}\right)\right)\end{array}$ & \\
\hline & & & ácido graso & Anandamida $\left(\mathrm{C}_{22} \mathrm{H}_{37} \mathrm{NO}_{2}\right)$ & \\
\hline & & & flavonoide & Genistein $\left(\mathrm{C}_{15} \mathrm{H}_{10} \mathrm{O}_{5}\right)$ & \\
\hline & & & \multicolumn{2}{|l|}{ tanino } & \\
\hline & & & isotiocianato & $\begin{array}{l}\text { 6-Methylthiohexyl isothiocyanate } \\
\qquad\left(\mathrm{C}_{8} \mathrm{H}_{15} \mathrm{~N}_{2}\right)\end{array}$ & Takasawa, et al. $(1990)^{\star \star}$ \\
\hline & & & alcaloide & $\begin{array}{l}\text { Capsaicina (8-methyl-N-vanil } \\
\text { lyl-6-nonenamide) }\end{array}$ & \multirow{2}{*}{ Xu, et al. (2005)* } \\
\hline & & & $\begin{array}{l}\text { ácido } \\
\text { zostérico }\end{array}$ & p-(sulfooxy) cinnamicacid & \\
\hline
\end{tabular}




\section{Anexo 2. Lista de organismos inhibidos por la acción de extractos compuestos o por moléculas derivadas de plantas terrestres.}

\begin{tabular}{|c|c|c|c|c|c|}
\hline \multicolumn{6}{|c|}{ Microfouling } \\
\hline Reino & Filo & Clase & Orden & Familia & Género \\
\hline Bacteria & Actinobacteria & Actinobacteria & Actinomycetales & Micrococcaceae & Micrococcus \\
\hline Bacteria & Bacteroidetes & Flavobacteria & Flavobacteriales & Flavobacteriaceae & Polaribacter \\
\hline Bacteria & Firmicutes & Bacilli & Bacillales & Bacillaceae & Bacilus \\
\hline Bacteria & Firmicutes & Bacili & Bacillales & Bacillaceae & Exiguobacterium \\
\hline Bacteria & Firmicutes & Bacilli & Lactobacillales & Enterococcaceae & Enterococcus \\
\hline Bacteria & Firmicutes & Bacilli & Bacillales & Staphylococcaceae & Staphylococcus \\
\hline Bacteria & Firmicutes & Bacilli & Bacillales & Staphylococcaceae & Salinicoccus \\
\hline Bacteria & Proteobacteria & Alphaproteobacteria & Rhodobacterales & Rhodobacteraceae & Phaeobacter \\
\hline Bacteria & Proteobacteria & Alphaproteobacteria & Rhodobacterales & Rhodobacteraceae & Roseobacter \\
\hline Bacteria & Proteobacteria & Gammaproteobacteria & Alteromonadales & Alteromonadaceae & Alteromonas \\
\hline Bacteria & Proteobacteria & Gammaproteobacteria & Alteromonadales & Alteromonadaceae & Marinobacter \\
\hline Bacteria & Proteobacteria & Gammaproteobacteria & Alteromonadales & Pseudoalteromonadaceae & Pseudoalteromonas \\
\hline Bacteria & Proteobacteria & Gammaproteobacteria & Alteromonadales & Pseudomonadaceae & Pseudomonas \\
\hline Bacteria & Proteobacteria & Gammaproteobacteria & Alteromonadales & Shewanellaceae & Shewanella \\
\hline Bacteria & Proteobacteria & Gammaproteobacteria & Oceanospirillales & Halomonadaceae & Cobetia \\
\hline Bacteria & Proteobacteria & Gammaproteobacteria & Enterobacteriales & Enterobacteriaceae & Escherichia \\
\hline Bacteria & Proteobacteria & Gammaproteobacteria & Enterobacteriales & Enterobacteriaceae & Salmonella \\
\hline Bacteria & Proteobacteria & Gammaproteobacteria & Oceanospirillales & Halomonadaceae & Halomonas \\
\hline Bacteria & Proteobacteria & Gammaproteobacteria & Oceanospirillales & Oceanospirillaceae & Marinomonas \\
\hline Bacteria & Proteobacteria & Gammaproteobacteria & Oceanospirillales & Oceanospirillaceae & Neptuniibacter \\
\hline Bacteria & Proteobacteria & Gammaproteobacteria & Oceanospirillales & Oceanospirillaceae & Oceanospirillum \\
\hline Bacteria & Proteobacteria & Gammaproteobacteria & Oceanospirillales & Oceanospirillaceae & Oleibacter \\
\hline Bacteria & Proteobacteria & Gammaproteobacteria & Thiotrichales & Piscirickettsiaceae & Methylophaga \\
\hline Bacteria & Proteobacteria & Gammaproteobacteria & Vibrionales & Vibrionaceae & Vibrio \\
\hline Chromista & Haptophyta & Prymnesiophyceae & Isochrysidales & Isochrysidaceae & Chrysotila \\
\hline Chromista & Ochrophyta & Bacillariophyceae & Bacillariales & Bacillariaceae & Cylindrotheca \\
\hline Chromista & Ochrophyta & Bacillariophyceae & Bacillariales & Bacillariaceae & Nitszchia \\
\hline Chromista & Ochrophyta & Bacillariophyceae & Melosirales & Melosiraceae & Melosira \\
\hline Chromista & Ochrophyta & Bacillariophyceae & Naviculales & Amphipleuraceae & Halamphora \\
\hline Chromista & Ochrophyta & Bacillariophyceae & Naviculales & Naviculaceae & Navicula \\
\hline Chromista & Ochrophyta & Bacillariophyceae & Naviculales & Pleurosigmataceae & Pleurosigma \\
\hline Chromista & Ochrophyta & Bacillariophyceae & Striatellales & Striatellaceae & Grammatophora \\
\hline Chromista & Ochrophyta & Bacillariophyceae & Thalassiophysales & Catenulaceae & Amphora \\
\hline Chromista & Ochrophyta & Bacillariophyceae & Thalassionematales & Thalassionemataceae & Thalassiothrix \\
\hline Plantae & Rhodophyta & Porphyridiophyceae & Porphyridiales & Porphyridiaceae & Porphyridium \\
\hline
\end{tabular}




\begin{tabular}{|c|c|c|c|c|c|}
\hline \multicolumn{6}{|c|}{ Macrofouling } \\
\hline Reino & Filo & Clase & Orden & Familia & Género \\
\hline Chromista & Ochrophyta & Phaeophyceae & Ectocarpales & Ectocarpaceae & Ectocarpus \\
\hline Plantae & Chlorophyta & Ulvophyceae & Ulvales & Ulvaceae & Ulva \\
\hline Animalia & Annelida & Polychaeta & Sabellida & Serpulidae & Hydroides \\
\hline Animalia & Annelida & Polychaeta & Sabellida & Serpulidae & Neodexiospira \\
\hline Animalia & Annelida & Polychaeta & Spionida & Spionidae & Boccardia \\
\hline Animalia & Arthropoda & Hexanauplia & Sessilia & Balanidae & Amphibalanus \\
\hline Animalia & Arthropoda & Hexanauplia & Sessilia & Balanidae & Chthamalus \\
\hline Animalia & Arthropoda & Malacostraca & Amphipoda & Corophiidae & Corophium \\
\hline Animalia & Bryozoa & Gymnolaemata & Cheilostomatida & Bugulidae & Bugula \\
\hline Animalia & Chordata & Ascidiacea & Phlebobranchia & Cionidae & Ciona \\
\hline Animalia & Mollusca & Bivalvia & Myida & Dreissenidae & Dreissena \\
\hline Animalia & Mollusca & Bivalvia & Mytilida & Mytilidae & Mytilus \\
\hline Animalia & Mollusca & Bivalvia & Ostreida & Ostreidae & Crassostrea \\
\hline
\end{tabular}

